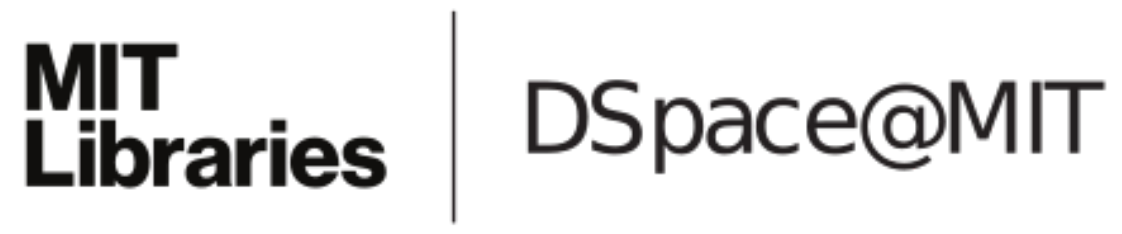

\author{
MIT Open Access Articles
}

Sub-picomolar Inhibition of HIV-1 Protease with a Boronic Acid

The MIT Faculty has made this article openly available. Please share how this access benefits you. Your story matters.

Citation: Windsor, Ian W. et al. "Sub-picomolar Inhibition of HIV-1 Protease with a Boronic Acid." Journal of the American Chemical Society 140, 43 (October 2018): 14015-14018 (C) 2018 American Chemical Society

As Published: http://dx.doi.org/10.1021/jacs.8b07366

Publisher: American Chemical Society (ACS)

Persistent URL: https://hdl.handle.net/1721.1/123666

Version: Author's final manuscript: final author's manuscript post peer review, without publisher's formatting or copy editing

Terms of Use: Article is made available in accordance with the publisher's policy and may be subject to US copyright law. Please refer to the publisher's site for terms of use. 
Published in final edited form as:

J Am Chem Soc. 2018 October 31; 140(43): 14015-14018. doi:10.1021/jacs.8b07366.

\title{
Sub-Picomolar Inhibition of HIV-1 Protease with a Boronic Acid
}

\author{
lan W. Windsor ${ }^{\dagger, \ddagger}$, Michael J. Palte§,\#, John C. Lukesh III ${ }^{\perp}$, Brian Gold ${ }^{\ddagger}$, Katrina T. \\ Forest $^{\star}, \perp, \|$, and Ronald T. Raines ${ }^{\star}, \dagger, \perp, \ddagger$ \\ †Department of Biochemistry, University of Wisconsin-Madison, Madison, Wisconsin 53706, \\ United States; \\ $\S$ Medical Scientist Training Program, University of Wisconsin-Madison, Madison, Wisconsin \\ 53706, United States; \\ \#Molecular \& Cellular Pharmacology Graduate Training Program, University of Wisconsin- \\ Madison, Madison, Wisconsin 53706, United States; \\ ${ }^{\perp}$ Department of Chemistry, University of Wisconsin-Madison, Madison, Wisconsin 53706, United \\ States; \\ "Department of Bacteriology, University of Wisconsin-Madison, Madison, Wisconsin 53706, \\ United States; \\ ‡Department of Chemistry, Massachusetts Institute of Technology, Cambridge, Massachusetts \\ 02139, United States
}

\begin{abstract}
Boronic acids have been typecast as moieties for covalent complexation and are employed only rarely as agents for noncovalent recognition. By exploiting the profuse ability of a boronic acid group to form hydrogen bonds, we have developed an inhibitor of HIV-1 protease with extraordinary affinity. Specifically, we find that replacing an aniline moiety in darunavir with a phenylboronic acid leads to 20 -fold greater affinity for the protease. X-Ray crystallography demonstrates that the boronic acid group participates in three hydrogen bonds, exceeding that of the amino group of darunavir or any other analog. Importantly, the boronic acid maintains its hydrogen bonds and its affinity for the drug-resistant D30N variant of HIV-1 protease. The $\mathrm{BOH} \cdots \mathrm{OC}$ hydrogen bonds between the boronic acid hydroxy group and Asp30 (or Asn30) of the protease are short $\left(r_{\mathrm{O}} \cdots \mathrm{O}=2.2 \AA\right)$, and density functional theory analysis reveals a high degree of covalency. These data highlight the utility of boronic acids as versatile functional groups in the design of small-molecule ligands.
\end{abstract}

\section{Graphical Abstract}

\footnotetext{
*Corresponding Authors: For K.T.F., forest@bact.wisc.edu. Tel: 608-265-3566, For R.T.R., rtraines@ mit.edu. Tel: 617-253-1470. Supporting Information

The Supporting Information is available free of charge on the ACS Publications website at DOI: 10.1021/jacs.xxxxxxx.

Experimental protocols and analytical data (PDF)

The authors declare no competing financial interest.
} 


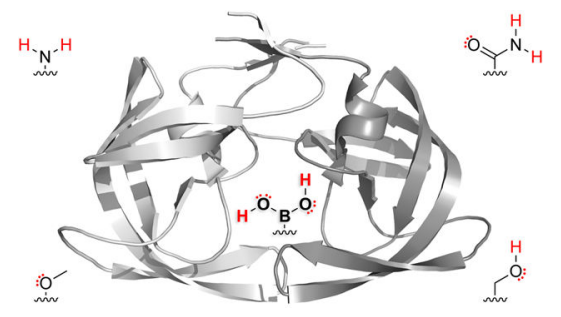

Clinical inhibitors of HIV-1 protease are quintessential triumphs of structure-based drug design. ${ }^{1}$ The protease cleaves diverse sequences that connect individual domains of viral polyproteins, recognizing four substrate residues on each side of the scissile bond. ${ }^{2}$ The components of most effective inhibitors-a tetrahedral-intermediate mimetic flanked by subsite-targeting groups-have undergone iterative optimization for 30 years. ${ }^{3}$ The discovery of the bis-THF moiety of darunavir, which targets the enzymic S2 subsite, was a major breakthrough. ${ }^{4}$ Its two bis-THF oxygen atoms accept hydrogen bonds from the mainchain amides of Asp29 and Asp30, leading to low picomolar affinity (Table 1). ${ }^{5}$ Mutations that overcome such main-chain interactions are rare, ${ }^{6}$ and darunavir is among the most resilient of protease inhibitors. ${ }^{7}$

Despite countless attempts at optimization, an ideal functional group for the $\mathrm{S}^{\prime}{ }^{\prime}$ subsite has been elusive. Inspection of structures of complexes between substrates and darunavir analogs (Table 1, Figure 1) in conjunction with biochemical characterization revealed opportunities to us. Half of endogenous substrates occupy the S2' subsite with a glutamine or glutamic acid residue. ${ }^{8,2}$ These side-chains have been observed to form hydrogen bonds with both the main-chain N-H and the side-chain carboxylate group of Asp30 (Figure 1A). The aniline nitrogen of darunavir and the methoxy group of an anisole analog form only a single hydrogen bond (Figures 1B and 1C). Benzyl alcohol and cyclopropyl-aminobenzothiazole groups can form two hydrogen bonds with Asp30, one with the main-chain $\mathrm{N}-\mathrm{H}$ and another with the side-chain (either via a water-bridge or directly), but provide $<2$ fold increases in affinity (Table 1, Figures 1D and 1E). Other aryl sulfonamide substituents, including benzoic acid and benzamide, form a water-bridge with Gly48 in addition to accepting a hydrogen bond from the main chain of Asp30, but again exhibit a $<2$-fold increase in affinity (Table 1, Figure 1F). This water-bridge with Gly48 is another interaction that can be exploited to recognize the main chain. Yet, no extant protease inhibitor interacts with all three of these targets: main chain and side chain of Asp30, and a water molecule that bridges to the main chain of Gly48.

We reasoned that an optimal functional group for targeting the $\mathrm{S}^{\prime}{ }^{\prime}$ subsite would serve as both a donor and an acceptor of hydrogen bonds. We were aware that the two hydroxy groups presented by boronic acids are versatile in this manner. ${ }^{12}$ These hydroxy groups display four lone pairs and two hydrogen-bond donors. No other functional group provides six opportunities to form hydrogen bonds so economically. We anticipated that one hydroxy group of a boronic acid could form both interactions with Asp30 while allowing the other hydroxy group to form a water-bridge with Gly48. Accordingly, we synthesized boronic acid 1, in which the 4-sulfonylaniline moiety of darunavir is replaced with a 4sulfonylphenylboronic acid (Table 1, Scheme S1). 
Boronic acid 1 is a competitive inhibitor of catalysis by HIV-1 protease. By using a hypersensitive assay of catalytic activity, ${ }^{9}$ we found its inhibition constant $\left(K_{\mathrm{i}}\right)$ to be 0.5 $\pm 0.3 \mathrm{pM}$, which is indicative of 20 -fold greater affinity compared to darunavir itself (Table 1, Figure S1D). Because the boronic acid moiety of $\mathbf{1}$ is anticipated to interact with Asp30, we suspected that D30N HIV-1 protease, which is a common variant that endows resistance, could compromise the affinity of boronic acid 1. For example, the D30N substitution entices darunavir to form a water-bridge between its aniline nitrogen and the nascent asparagine, diminishing affinity by 30 -fold. ${ }^{13}$ Remarkably, the affinity of boronic acid $\mathbf{1}$ for the D30N variant $\left(K_{\mathrm{i}}=0.4 \pm 0.3 \mathrm{pM}\right)$ is indistinguishable from that for wild-type HIV-1 protease.

To understand the basis for the extraordinary affinity and resiliency of boronic acid $\mathbf{1}$, we determined the X-ray crystal structures of its complexes with both wild-type HIV-1 protease and the D30N variant. The two structures were solved at resolutions of $1.60 \AA$ ( $R_{\text {free }}=$ $0.1967)$ and $1.94 \AA\left(R_{\text {free }}=0.2203\right)$, respectively (Table S1, Figure S2). True to its design, the boronic acid participated in all three hydrogen-bonding interactions (Figures $1 \mathrm{G}$ and $1 \mathrm{H}$ ). Of special note are $\mathrm{BOH} \cdots$ OC hydrogen bonds observed in both structures (Figures $1 \mathrm{G}$ and $1 \mathrm{H})$. The interatomic distance of $2.2 \AA$ between the boronate oxygen and side-chain $\mathrm{O}^{\delta}$ of residue 30 is reminiscent of a low-barrier hydrogen bond (LBHB). ${ }^{14}$

We analyzed the atypically short hydrogen bonds between boronic acid 1 and HIV-1 protease with computational methods. First, we optimized the hydrogen atoms by applying density functional theory (DFT) to a simple model extracted from the crystal structure. We examined the electronic structure by using Natural Bonding Orbital (NBO) analysis. ${ }^{15}$ NBO analysis revealed an interaction energy of $69.8 \mathrm{kcal} / \mathrm{mol}$ between boronic acid 1 and the wild-type protease. The typically non-hybridized $p$-type lone pair of the carboxylate oxygen hybridizes to $s p^{3.99}$ in the hydrogen-bonded complex. This large interaction energy and hybridization suggest a large degree of covalency in the $\mathrm{BOH} \cdots \mathrm{OC}$ hydrogen bond. Next, we assessed the covalency of the short hydrogen bond between boronic acid $\mathbf{1}$ and the wild-type protease with quantum theory of atoms in molecules (AIM). ${ }^{16}$ AIM calculationsspecifically, structural elements at the bond critical point (BCP) —enable quantification of the covalency between neighboring atoms. At the $\mathrm{BOH} \cdots \mathrm{OC} \mathrm{BCP}$, we calculated an electron density $(\rho)$ of $0.174 e \AA^{-3}$, a Laplacian $\left(\nabla^{2} \rho\right)$ of $-0.08 e \AA^{-5}$, and a bond index of 0.22 . Typical $\mathrm{OH} \cdots \mathrm{OC}$ hydrogen bonds display $\rho<0.2 e \AA^{-3}$, positive $\Delta^{2} \rho$ values, and a bond index $<0.1{ }^{17}$ Instead, the attributes of $\mathrm{BOH} \cdots \mathrm{OC}$ are consistent with the attributes of an LBHB. ${ }^{14}$

An LBHB arises from functional groups with closely matched $\mathrm{p} K_{\mathrm{a}}$ values. ${ }^{14}$ This requirement can be met by a carboxylic acid and a boronic acid, ${ }^{18}$ which are isoelectronic. In the enzyme-inhibitor complex (Figure $1 \mathrm{G}$ ), the boronic acid group of $\mathbf{1}$ displays an $n_{\mathrm{O}, p} \rightarrow p_{\mathrm{B}}$ interaction (i.e., resonance) of $89.1 \mathrm{kcal} / \mathrm{mol}$, and the carboxylic acid group of Asp30 in HIV-1 protease displays a comparable $n_{\mathrm{O}, p} \rightarrow \pi{ }^{*} \mathrm{C}=\mathrm{O}$ interaction of $87.9 \mathrm{kcal} / \mathrm{mol}$. The ensuing hyperconjugative interaction between a boronic acid and carboxyl acid is reminiscent of a resonance-assisted hydrogen bond. ${ }^{19}$ Such hyperconjugation is absent in other inhibitors, such as the benzyl alcohol analog of darunavir (Figure 1D). 
Boronic acids possess attractive properties beyond their versatile hydrogen bonding. Boronic acid 1, like darunavir, is not toxic to human cells at concentrations up to $1 \mathrm{mM}$ (Figure S3). In vivo, aniline moieties can exhibit problematic genotoxicity as a result of metabolic activation. ${ }^{20}$ In contrast, the major metabolite of boronic acids is the oxidative deboronation product, an alcohol, which is modified further in phase II metabolism for efficient excretion. 21,22

We conclude that a boronic acid group in a ligand can be profuse and versatile in forming hydrogen bonds with a protein. These attributes are especially valuable in the design of ligands for proteins that are under the selective pressure of drug resistance. In those instances, the ability of boronic acids to form multiple hydrogen bonds enhances affinity, and the admixture of hydrogen-bond acceptors and donors enables adaption to mutations.

\section{Supplementary Material}

Refer to Web version on PubMed Central for supplementary material.

\section{ACKNOWLEDGMENTS}

I.W.W. was supported by Biotechnology Training Grant T32 GM008349 (NIH) and a Genentech predoctoral fellowship. M.J.P. was supported by Molecular and Cellular Pharmacology Training Grant T32 GM008688 (NIH) and American Heart Association predoctoral fellowship 09PRE2260125. B.G. was supported by an Arnold O. Beckman Postdoctoral Fellowship. This work was supported by Grants R01 GM044783 (NIH) and MCB 1518160 (NSF), and made use of NMRFAM (University of Wisconsin-Madison), which is supported by Grant P41 GM103399 (NIH). This research used resources of the Advanced Photon Source, a U.S. Department of Energy (DOE) Office of Science User Facility operated for the DOE Office of Science by Argonne National Laboratory under Contract No. DE-AC02-06CH11357. Use of the LS-CAT Sector 21 was supported by the Michigan Economic Development Corporation and the Michigan Technology Tri-Corridor (Grant 085P1000817).

\section{REFERENCES}

(1). (a)Vondrasek J; Wlodawer A Annu. Rev. Biophys. Biomol. Struct 1998, 27, 249-284. [PubMed: 9646869] (b)Ghosh AK, Ed. Aspartic Acid Proteases as Therapeutic Targets. Wiley-VCH: Weinheim, Germany, 2010.

(2). Prabu-Jeyabalan M; Nalivaika E; Schiffer CA Structure 2002, 10, 369-381. [PubMed: 12005435]

(3). Ripka AS; Rich DH Curr. Opin. Chem. Biol 1998, 2, 441-452. [PubMed: 9736916]

(4). Ghosh AK; Kincaid JF; Cho W; Walters DE; Krishnan K; Hussain KA; Koo Y; Cho H; Rudall C; Holland L; Buthod J Bioorg. Med. Chem. Lett 1998, 8, 687-90. [PubMed: 9871583]

(5). (a)Koh Y; Nakata H; Maeda K; Ogata H; Bilcer G; Devasamudram T; Kincaid JF; Boross P; Wang YF; Tie Y; Volarath P; Gaddis L; Harrison RW; Weber IT; Ghosh AK; Mitsuya H Antimicrob. Agents Chemother 2003, 47, 3123-3129. [PubMed: 14506019] (b)Ghosh AK; Dawson ZL; Mitsuya H Bioorg. Med. Chem 2007, 15, 7576-7580. [PubMed: 17900913]

(6). (a)King NM; Prabu-Jeyabalan M; Nalivaika EA; Schiffer CA Chem. Biol 2004, 11, 1333-1338. [PubMed: 15489160] (b)Agniswamy J; Shen CH; Aniana A; Sayer JM; Louis JM; Weber IT Biochemistry 2012, 51, 2819-2828. [PubMed: 22404139] (c)de Vera IM; Blackburn ME; Fanucci GE Biochemistry 2012, 51, 7813-7815. [PubMed: 23009326] (d)Zhang Y; Chang YC; Louis JM; Wang YF; Harrison RW; Weber IT ACS Chem. Biol 2014, 9, 1351-1358. [PubMed: 24738918]

(7). (a)Ghosh AK; Sridhar PR; Leshchenko S; Hussain AK; Li J; Kovalevsky AY; Walters DE; Wedekind JE; Grum-Tokars V; Das D; Koh Y; Maeda K; Gatanaga H; Weber IT; Mitsuya H J. Med. Chem 2006, 49, 5252-5261. [PubMed: 16913714] (b)Lefebvre E; Schiffer CA AIDS Rev. 2008, 10, 131-142. [PubMed: 18820715] (c)Nalam MN; Ali A; Reddy GS; Cao H; Anjum SG; 
Altman MD; Yilmaz NK; Tidor B; Rana TM; Schiffer ,CA Chem. Biol 2013, 20, 1116-1124. [PubMed: 24012370]

(8). (a)Weber IT; Wu J; Adomat J; Harrison RW; Kimmel AR; Wondrak EM; Louis JM Eur. J. Biochem 1997, 249, 523-530. [PubMed: 9370363] (b)Beck ZQ; Hervio L; Dawson PE; Elder JH; Madison EL Virology 2000, 274, 391-401. [PubMed: 10964781]

(9). Windsor IW; Raines RT Sci. Rep 2015, 5, 11286. [PubMed: 26261098]

(10). Yedidi RS; Maeda K; Fyvie WS; Steffey M; Davis DA; Palmer I; Aoki M; Kaufman JD; Stahl SJ; Garimella H; Das D; Wingfield PT; Ghosh AK; Mitsuya H Antimicrob. Agents Chemother 2013, 57, 4920-4927. [PubMed: 23877703]

(11). Ghosh AK; Rao KV; Nyalapatla PR; Osswald HL; Martyr CD; Aoki M; Hayashi H; Agniswamy J; Wang YF; Bulut H; Das D; Weber IT; Mitsuya HJ Med. Chem 2017, 60, 4267-4278.

(12). (a)Hall DG, Ed. Boronic Acids: Preparation and Applications in Organic Synthesis, Medicine and Materials, 2nd ed Wiley-VCH: Weinheim, Germany, 2011.(b)Tzeli D; Theodorakopoulos G; Petsalakis ID; Ajami D; Rebek JJ Am. Chem. Soc 2011, 133, 16977-16985.(c)Diaz DB; Yudin AK Nat. Chem 2017, 9, 731-742. [PubMed: 28754930]

(13). Kovalevsky AY; Tie Y; Liu F; Boross PI; Wang Y-F; Leshchenko S; Ghosh AK; Harrison RW; Weber IT J. Med. Chem 2006, 49, 1379-1387. [PubMed: 16480273]

(14). (a)Cleland WW; Frey PA; Gerlt JA J. Biol. Chem 1998, 273, 25529-25532. [PubMed: 9748211] (b)Perrin CL Acc. Chem. Res 2010, 43, 1550-1557. [PubMed: 20939528]

(15). Weinhold FJ Comput. Chem 2012, 33, 2363-2379.

(16). Bader RF W. Chem. Rev 1991, 91, 893-928.

(17). Schiott B; Iversen BB; Madsen GK; Larsen FK; Bruice TC Proc. Natl. Acad. Sci. USA 1998, 95, 12799-12802. [PubMed: 9788994]

(18). The pKa of phenylboronic acid is 8.9 (Westmark PR; Gardiner SJ; Smith BD J. Am. Chem. Soc 1996, 118, 11093-11100).

(19). (a)Gilli G; Bellucci F; Ferretti V; Bertolasi V J. Am. Chem. Soc 1989, 111, 1023-1028.(b)Góra RW; Maj M; Grabowski SJ Phys. Chem. Chem. Phys 2013, 15, 2514-2522. [PubMed: 23322083] (c)Grosch AA; van der Lubbe SCC; Fonseca GC J. Phys. Chem. A 2018, 122, 18131820. [PubMed: 29357252]

(20). (a)Gentile JM; Gentile GJ; Plewa MJ Mutat. Res 1987, 188, 185-196. [PubMed: 3600686] (b)Bomhard EM; Herbold BA Crit. Rev. Toxicol 2005, 35, 783-835. [PubMed: 16468500] (c)Makhdoumi P; Limoee M; Ashraf GM; Hossini H Curr. Neuropharmacol 2018, DOI : 10.2174/1570159X16666180803164238.

(21). (a)Pekol T; Daniels JS; Labutti J; Parsons I; Nix D; Baronas E; Hsieh F; Gan LS; Miwa G Drug Metab. Dispos 2005, 33, 771-777. [PubMed: 15764713] (b)Bu W; Akama T; Chanda S; Sullivan D; Ciaravino V; Jarnagin K; Freund Y; Sanders V; Chen C-W; Fan X; Heyman I; Liu LJ Pharm. Biomed. Anal 2012, 70, 344-353.

(22). Notably, a growing number of boronic acids are achieving clinical utility.Raedler LA Am. Health Drug Benefits 2016, 9, 102-105. [PubMed: 27668055] Kailas A Dermatol. Ther 2017, 30, e12533. 


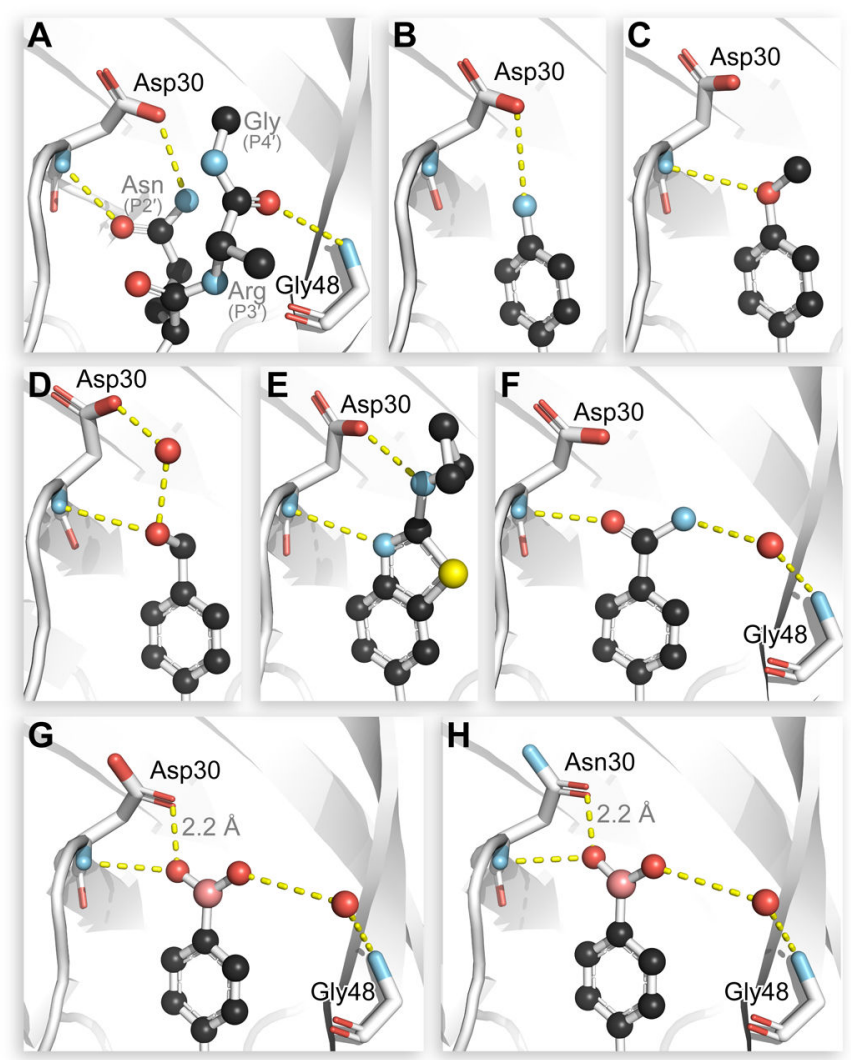

Figure 1.

Interactions with a substrate, darunavir, or its analogs and the S2' subsite of HIV-1 protease. (A) A substrate (PDB entry 1kj7). (B) Darunavir (4hla). (C) Anisole analog (2i4u). (D) Benzyl alcohol analog (3o9g). (E) Cyclopropyl-amino-benzothiazole analog (5tyr). (F) Benzamide analog (4i8z). (G) Boronic acid 1 bound to wild-type HIV-1 protease (6c8x). (H) Boronic acid 1 bound to D30N HIV-1 protease (6c8y). Major conformers are shown for inhibitors that bound in non-symmetry-related conformations. 
A

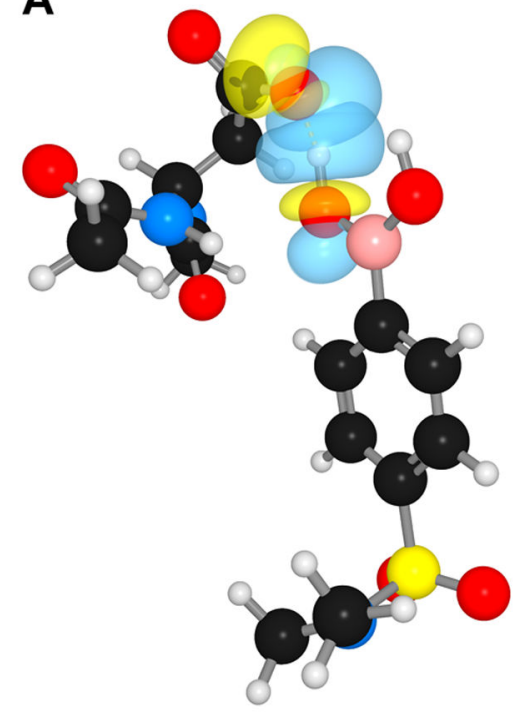

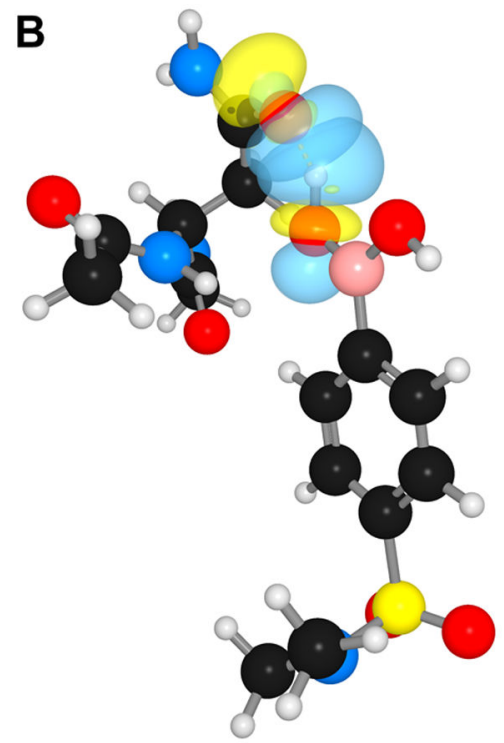

Figure 2.

Orbital interactions in a model of boronic acid 1 and residue 30 of HIV-1 protease derived from X-ray crystal structures (PDB entries $6 \mathrm{c} 8 \mathrm{x}$ and $6 \mathrm{c} 8 \mathrm{y}$ ). NBO rendering of the hydrogen bond between a boronic acid hydroxy group and $\mathrm{O}^{\delta}$ of Asp30 (A) and Asn30 (B) with hydrogen atoms optimized at the M06-2X/6-311+G(d,p) level of theory employing the IEFPCM solvation model. 
Table 1.

Values of Ki for Inhibition of HIV-1 Protease

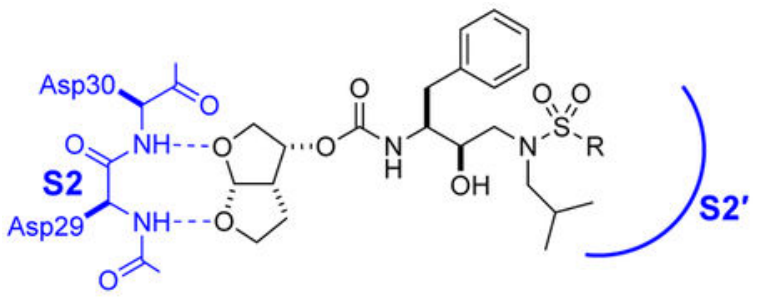

\begin{tabular}{llll}
\hline R & $K_{\mathrm{i}}(\mathrm{pM})$ & Relative Affinity & \\
\end{tabular}<smiles>Cc1ccc(N)cc1</smiles>

darunavir<smiles>COc1ccc(C)cc1</smiles><smiles>Cc1ccc(CO)cc1</smiles>

12

1.2

$1 \mathrm{~b}$<smiles>Cc1ccc(C(=O)O)cc1</smiles><smiles>Cc1ccc2nc(NC(C)C)sc2c1</smiles><smiles>Cc1ccc(C(N)=O)cc1</smiles> 


\begin{tabular}{|c|c|c|c|}
\hline $\mathbf{R}$ & $K_{\mathrm{i}}(\mathbf{p M})$ & Relative Affinity ${ }^{a}$ & Ref. \\
\hline & $0.5 \pm 0.3$ & 20 & This work \\
\hline 1 & & & \\
\hline
\end{tabular}

${ }^{a}$ Values of $K_{\mathrm{i}}$ can depend on assay conditions. Here, values are compared by using darunavir as a benchmark with Relative Affinity = $K_{\mathrm{i}, \text { darunavir }} / K_{\mathrm{i}, \text { analog }}$ as reported in the indicated reference. 